\title{
Development of a technique for improving access to farm practice information based on monitored temperature conditions
}

\author{
Ewang Essien Sampson ${ }^{1,}$, , Thomas Kokumo Yesufu ${ }^{2}$ \\ ${ }^{1}$ Department of Research and Development, ARCSSTE-E, O.A.U. Campus Ile-Ife, Osun, Nigeria \\ ${ }^{2}$ Department of Electronic and Electrical Engineering, Obafemi Awolowo University, Ile- Ife, Osun, Nigeria
}

\section{Email address:}

ewang_arcsste@yahoo.com(E. E. Sampson), Thomas_yesufu@yahoo(T. K. Yesufu)

\section{To cite this article:}

Ewang Essien Sampson, Thomas Kokumo Yesufu. Development of a Technique for Improving Access to Farm Practice Information Based on Monitored Temperature Conditions. International Journal of Science, Technology and Society. Vol. 2, No. 6, 2014, pp. 165-173. doi: $10.11648 /$ j.jijsts.20140206.11

\begin{abstract}
The study designed and implemented a temperature monitoring system. The system generated timely an accurately farm practice information from monitored temperature data. This was with a view to providing critical information in advance to farmers for making proper agricultural farm management decisions. A system that monitored soil temperature at an interval of 10 minutes in a Metrological Station was set up. This comprised of a programmable interface controller (PIC) 18F452, temperature sensor, real time clock DS1307RTC and micro secure digital memory card with adapter in normal SD card application. The circuit was designed with Proteus Institute for Software Integrated Systems (ISIS) and the components were placed on the Vero board as laid out in the circuit diagram and then soldered. The firmware, written with $\mathrm{C}$ programming language, compiled, using Custom Computer Service Compiler (CCS C) for PIC. Subsequently, calibration was carried out and the readings from the device were validated and benchmarked with that of the standard analogue thermometer and automated data systems. Furthermore, the results were examined statistically using Auto-Regressive Integrated Moving Average (ARIMA) model with expert modeler, to predict the soil temperature and obtain farm practice information based on the recorded values. A Short Message Service (SMS) application interface was developed for Global System for Mobile Communication (GSM) module (SIM300) using visual C\# programming language. The paired t-test from the analysis showed that there was no significant difference $(p>0.05)$ and there were positive correlations between the designed temperature system, a standard analog thermometer and an automated data logging system. From the family of the identified models, ARIMA $(0,1,0)$ model was found to be the most adequate model that really captured the dependence in the series. The performance evaluations of the adopted model was carried out on the basis of correlation coefficient (R2) and Ljung-Box statistics with values of 0.95, 13.58 and $0.96,19.75$ respectively for soil temperature at $5 \mathrm{~cm}$ and 10 $\mathrm{cm}$ soil depths. The model was used for forecast from weeks 11- 35, 2013. The result of the analysis from the graph of the predicted soil temperature at $5 \mathrm{~cm}$ soil depth showed that between weeks $21-43$ and $18-35$ fell between $10^{\circ} \mathrm{C}$ and $30^{\circ} \mathrm{C}$. Within these periods maize seeds could be planted. The developed technique would provide an improved access to farm practice information based on monitored soil temperature conditions and, thereby, bring about better decision making by related stakeholders.
\end{abstract}

Keywords: Farm Practice, Information, Temperature Conditions

\section{Introduction}

Improved access to farm practice information based on the monitored temperature condition is very vital in agricultural development of any community. Temperature condition is monitor as the result of the climate variability that plays a significant role in daily life and development in an environment. Such variability has major impact on nearly all inhabitants of the region, ranging from health, energy, access to water, food security, and perhaps political stability (Raleigh and Urdal, 2007). One significant group of people that bears much of these burdens is the farmers, whose crops are dependent on proper environmental conditions. Improving farmer access to this information can help to improve by reducing the impacts of climate variability on this vulnerable population: the seasonal climate forecast. Soil temperature could provide the basic information for making proper farm 
management decisions due to this climate variability. Although this parameter is frequently measured, many farmers are yet to benefit from this critical information sufficiently in advance. Soil temperature is one of the important soil characteristics that affect seed germination, growth of plant and also microbial life in soil (Adelekun, 2012). Soil temperature measurement is important in studying how extreme temperatures can limit the availability of water to the roots of crop plant and cause water deficit stress (Gavito et al., 2001; Lambers et al., 2008). It varies greatly daily, weekly and seasonally as affected by variations in air temperature. Based on these, there is a need to monitor the temperature of the soil so as to safeguard against its adverse effects on soil flora and fauna. When farmers lack access to knowledge and information that would help them achieve maximum agricultural yield, they not only grope in the dark but are driven to the urban centers in search of formal employment, as the only option for survival (Munyua, 2000). Improving farmer access to information sufficiently in advance can help to improve farm operations in a way that not only minimizes the costs and crop losses but also helps in maximizing the yield gains. This can also help them to adopt suitable management techniques and mitigate the ill effects on crops. One of the key challenges to the development of detailed climate change predictions in Nigeria is the lack of access to available local climate information. The current infrastructure in Nigeria is often not as reliable or powerful as more developed countries. For example, Africa including Nigeria has an inadequate number of meteorological stations for climate data collection, and much of the data that exists has not been digitized (UNFCC, 2007). In addition to the limited available data and information, in many countries there is an insufficient exchange of information and a limited number of networking systems (Ogallo, 2010). The lack of access to reliable telecommunications network in Nigeria, including internet access is a strong limiting factor in exchanging information. There are also many countries that are not aware of the opportunity to link with existing knowledge platforms or develop partnerships with research institutes, universities and scientific organizations (Ogallo, 2010). In recent years, many new initiatives have been developed in Nigeria to expand and improve access to climate data. These include designing and setting up a national climate change knowledge platform that will serve as a repository for data and studies to support information and data sharing, linked with the Adaptation Learning Mechanism; and commissioning the development of knowledge products required for the awareness-raising and targeted training activities. Improving access to both historical and projected climate data through such partnerships and knowledge platforms could help farmers increase knowledge and awareness of climate change impacts and adaptation strategies. Aina (2007) was of the opinion that farmers would benefit from global information, if information centers are cited in rural areas complete with all information and communication gadgets. Several place-based studies have highlighted communication as a key weakness in the ability of the climate information system to serve the agricultural sector (Pulwarty et al., 2009). This weakness has been well documented for some time in the forecast applications literature, yet remains of critical importance. To overcome this, and to have easy access and effective utilization of agricultural information in this digital era, there is need for establishment of information centres in all rural communities in Nigeria. Such information centres should be able to provide the rural farmers with the desired agricultural information in a format that would be comprehensible to them, taking into cognizance the prevailing high illiteracy rate, cultural differences and limited technology.

A temperature monitoring system is an electronic device with temperature sensor attached to keep a record of the temperature in relation to location at various intervals, so that the data can be retrieved later for further analysis or forecasting. Temperature monitoring systems have been used in diverse fields, among others is in agricultural sector. Al-Ali et al. (2004) developed a system which allows the industrial owner to monitor and control his house appliances via his mobile phone set. And by sending commands in the form of SMS messages and receiving the appliances status as well. Romilly (2005) applied ARIMA time's series model to develop a forecasting model for global mean temperature. Mohd et al. (2008) developed a system that could remotely monitor and predict changes of temperature level in agricultural greenhouse. This system had the capability of sending alert notification messages to farmers using GSM and SMS technology. Ramamurthy et al., (2010) developed a Low-Cost GSM SMS-Based Humidity Remote Monitoring and Control system for Industrial Applications. This was for a control that used the combination of an embedded system and a GSM communications module linked by a serial communications port. The design was such that, whenever relative humidity crosses the set limit, the ARM processor will send an alert to a concerned authority(s) mobile phone. To date, various studies have been carried out on this area but little effort has been made in this region. Thus, this paper aimed at the design and implementation of a microcontroller based temperature monitoring system, predict farm practice information from monitored temperature conditions; and generate timely and accurate farm practice information for here in the tropical region.

\subsection{Study area}

This study was carried out at Soil Science Laboratory, Soil Science and Nimex Meteorological station, Department of physics; Electronic and Electrical Engineering Department, Obafemi Awolowo University, IIe-Ife, Nigeria. Obafemi Awolowo University, IIe-Ife is located between latitude $7^{\circ}$ $33.308^{\prime} \mathrm{N}$ and longitude $4^{\circ} 33.466^{\prime} \mathrm{E}$ to $7^{\circ} 33.267^{\prime} \mathrm{N}$ and $4^{\circ} 33.466^{\prime}$ E. It is located in the rain forest ecosystem in the South-western region of Nigeria with a mean annual rainfall of about $1,400 \mathrm{~mm}$ which is bimodally distributed with peaks in June and September. The nature of soil in this allocation is clay loam. 


\section{Materials and Methods}

A system for monitoring soil temperature at an interval of ten minutes for the period of study on clay loam soil was set up from 12th April to 22nd April, 2013 at Nigerian Micrometeorological Experiment (NIMEX) station, Department of physics, Obafemi Awolowo University, Ile-Ife, Nigeria. This comprises of the PIC18F452, temperature sensor LM35 probe, DS1307RTC (real time clock) timer and micro SD with adapter normal SD card application. The circuit was designed with Proteus ISIS and the components were placed on the Vero board as laid out in the circuit diagram and then soldered as in Fig. 1. The firmware, written with $\mathrm{C}$ programming language, compiled into assembly code and executable hexadecimal file, using CCSC compiler for PIC. The code was then written into Microprocessor chip, using Usbpicprog, an usb in circuit programmer for Microchip PIC processors. Subsequently, calibration was carried out and the readings from the device were validated and benchmarked by taking sample readings and correlating them with readings that from the standard analog thermometer and automated data systems. The temperature data acquisition system sampling time was set to every 10 seconds and record data at intervals of 10 minutes in line with an existing one (NIMEX weather station on O.A.U site). The micro SD card was used as a mean to download the data manually from designed system into personal computer. In this study soil temperature was measured at 5,10 , and $20 \mathrm{~cm}$ depths from soil surface, indicated by the three channels of the system, compared with standard temperature obtained from clinical thermometer. The results were analyzed with the aid of computer Programs using the toolbox of the MATLAB software and statistically using SPSS. A snapshot of designed temperature data monitoring system that shows Vero board layout and internal Components is as shown in Fig. 2. This study led to the building of a suitable parsimonious mathematical time series model that can predict the future soil temperature based on the recorded data. A popularly recognized Box-Jenkins modeling approach was used to identify and estimate the parameters of the identified models for the series. The original series was not stationary and there were strong indications of autocorrelation and possible seasonality in the series. Stationarity was achieved after a first order differencing; the series were transformed to stationarity by taking the natural $\log$ and by taking a difference. After first differencing and given enough lag intervals of 35 , the figures of ACF shown that variables were not periodic in nature. Therefore these given time series were not periodic and did not involve seasonal variations. As the result the downward trend at week 31was disappeared shown in Fig. 11 and replaced by peaks and troughs of various weeks, but of non-periodic interval. The spikeless graph produced at first differencing at various lags suggested fitting a non-seasonal ARIMA $(0,1,0)$ into the series. The Expert Modeler within software tool SPSS was used to automatically find the best-fitting model for each dependent series. This selects, for inclusion in ARIMA models those independence variables that have a statistically significant relationship with the dependent series.

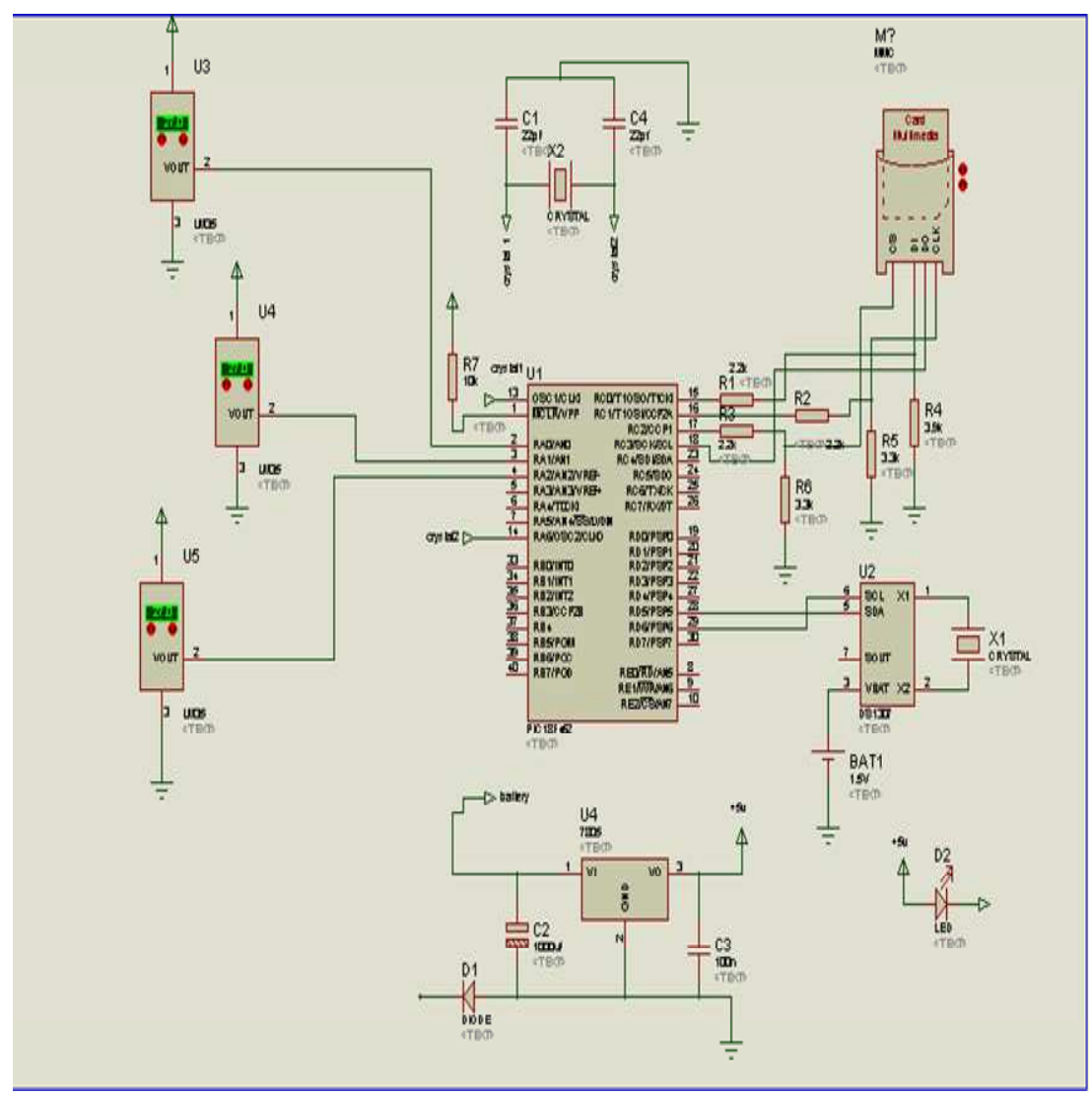

Fig 1. Full Circuit Diagram of PIC18F452-Based Temperature Monitoring System 


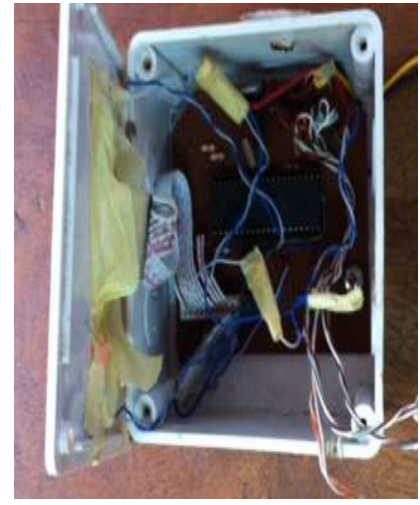

Fig 2. A Snapshot of the Designed Microcontroller-Based Temperature Monitoring System showing Vero Board layout and Internal Components

levels of significance. ARIMA models can predict soil temperature with good accuracy as indicated by statistics model, ARIMA model parameters and model fit. At the end, a short term forecasting was done using the chosen model and the results of the findings were fully interpreted. Finally, the result of this analysis which is farm practice information based on the planting date for maize, was sent to the farmers' phones. This was possible by interfacing the GSM module to PC through the SMS application developed using visual c\# programming language. Developing such a means of generating this information to farmers assists in improving access to information based on the stored data.

\section{Results and Discussion}

Three parameters of the model namely; air temperature, global solar and soil heat flux were significant at all chosen

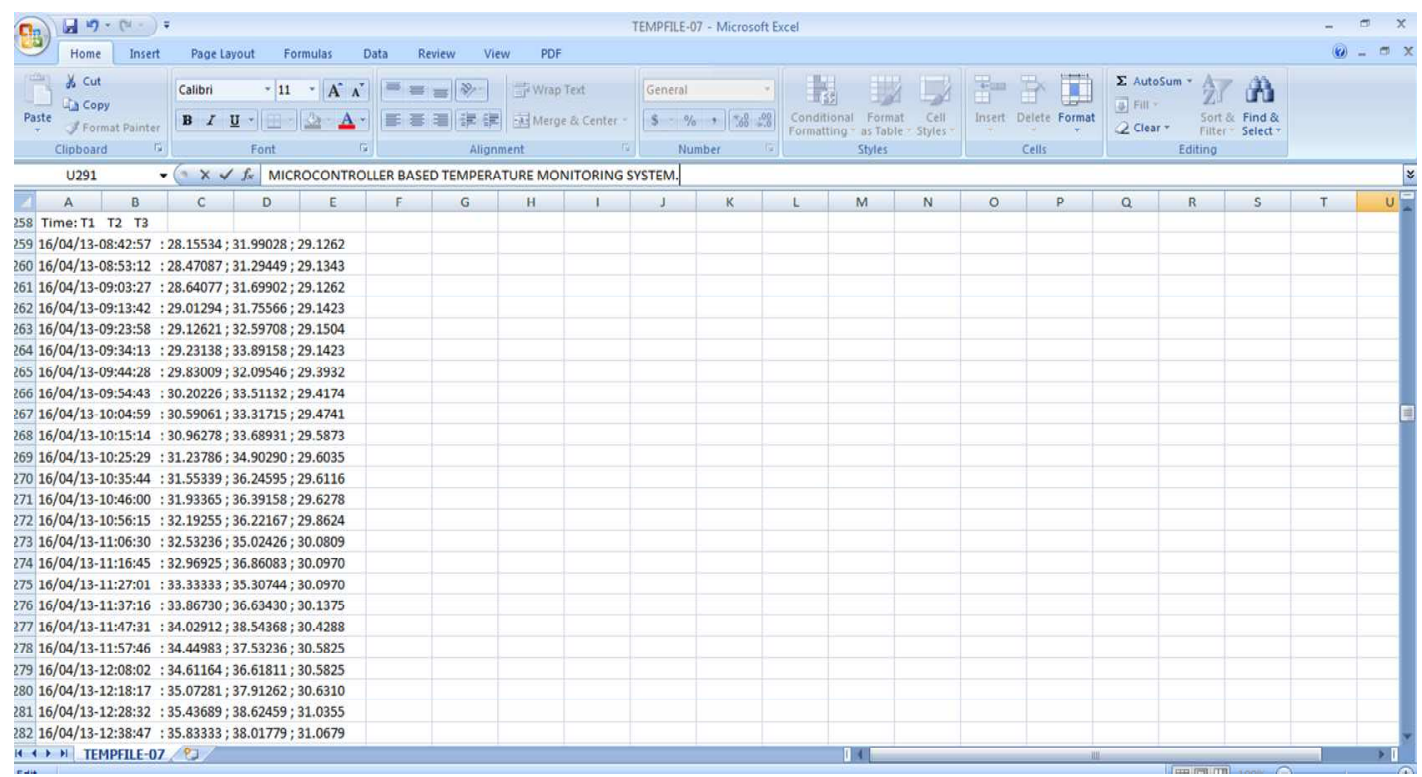

Fig 3. Graphic User Interface of Microcontroller-Based Temperature Monitoring System.

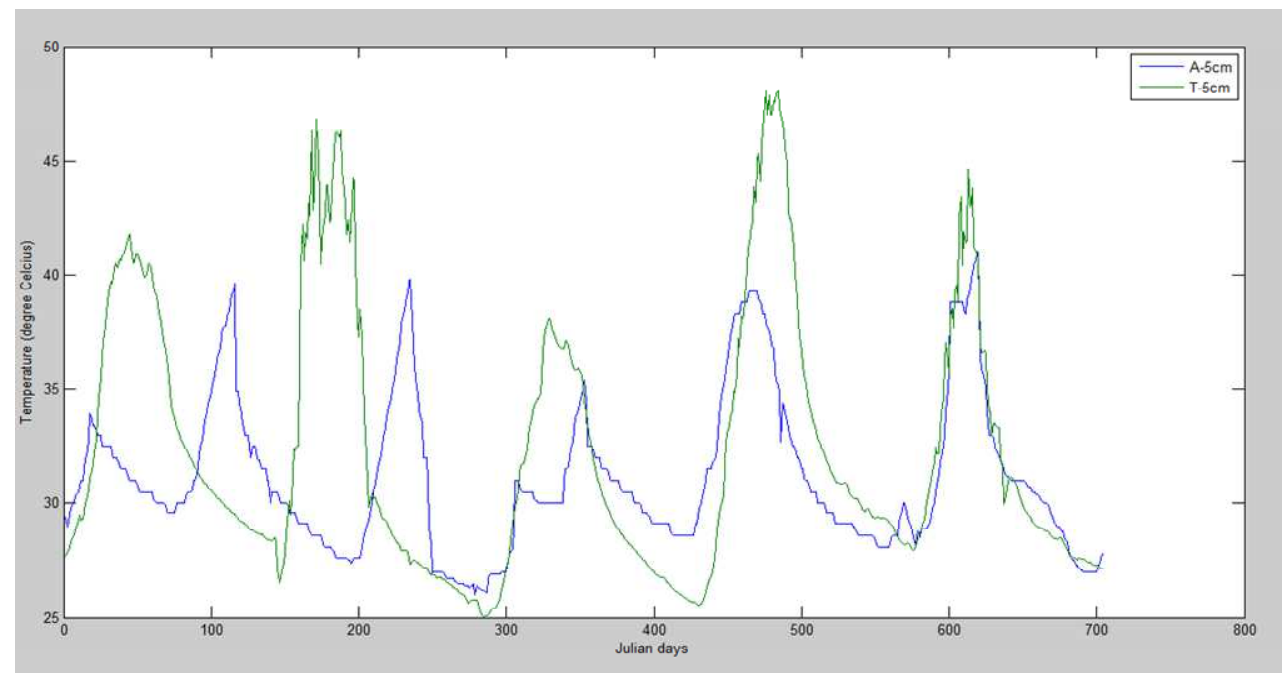

Fig 4. Comparison of Temperature Readings at $5 \mathrm{~cm}$ Depth of the Designed Temperature System with $5 \mathrm{~cm}$ Depth of NIMEX Soil Temperature Data Logger. 
Table 1. Average reading taken for twenty four readings each from the designed and the standard thermometer at NIMEX station spread over twelve hours in the morning, after moon, and evening

\begin{tabular}{lllll}
\hline N/S & Sensor and its depth & N & Correlation & Sig. \\
\hline Pair 1 & $\begin{array}{l}\text { Temp_5cm \& } \\
\text { Analog_5cm } \\
\text { Pemp_10 }\end{array}$ & 24 & 0.972 & 0.000 \\
\hline & $\begin{array}{l}\text { Analog_10 } ~\end{array}$ \\
\hline
\end{tabular}

Table 2. Checking for Autocorrelations in Series T1 5

\begin{tabular}{|c|c|c|c|c|c|}
\hline \multirow{2}{*}{ Lag } & \multirow{2}{*}{$\begin{array}{l}\text { Autocorrelatio } \\
\text { n }\end{array}$} & \multirow{2}{*}{ Std. Errora } & \multicolumn{3}{|c|}{ Box-Ljung Statistic } \\
\hline & & & Value & df & Sig.b \\
\hline 1 & -.208 & .139 & 2.242 & 1 & .134 \\
\hline 2 & -.142 & .137 & 3.311 & 2 & .191 \\
\hline 3 & -.073 & .136 & 3.598 & 3 & .308 \\
\hline 4 & .135 & .134 & 4.610 & 4 & .330 \\
\hline 5 & .200 & .133 & 6.872 & 5 & .230 \\
\hline 6 & -.009 & .131 & 6.877 & 6 & .332 \\
\hline 7 & -.151 & .130 & 8.227 & 7 & .313 \\
\hline 8 & .089 & .128 & 8.710 & 8 & .367 \\
\hline 9 & .046 & .127 & 8.842 & 9 & .452 \\
\hline 10 & .240 & .125 & 12.54 & 10 & .250 \\
\hline 11 & -.241 & .123 & 16.35 & 11 & .129 \\
\hline 12 & -.021 & .122 & 16.38 & 12 & .174 \\
\hline 13 & .037 & .120 & 16.47 & 13 & .224 \\
\hline 14 & .075 & .118 & 16.88 & 14 & .262 \\
\hline 15 & -.054 & .117 & 17.09 & 15 & .313 \\
\hline 16 & -.061 & .115 & 17.38 & 16 & .361 \\
\hline 17 & -.005 & .113 & 17.38 & 17 & .429 \\
\hline 18 & -.053 & .111 & 17.60 & 18 & .482 \\
\hline 19 & -.046 & .110 & 17.77 & 19 & .537 \\
\hline 20 & .059 & .108 & 18.07 & 20 & .582 \\
\hline 21 & -.108 & .106 & 19.11 & 21 & .578 \\
\hline 22 & -.049 & .104 & 19.33 & 22 & .625 \\
\hline 23 & .000 & .102 & 19.33 & 23 & .682 \\
\hline 24 & -.078 & .100 & 19.93 & 24 & .700 \\
\hline 25 & -.005 & .098 & 19.93 & 25 & .750 \\
\hline 26 & -.011 & .096 & 19.95 & 26 & .794 \\
\hline 27 & -.023 & .094 & 20.01 & 27 & .830 \\
\hline 28 & -.087 & .092 & 20.90 & 28 & .829 \\
\hline 29 & -.032 & .089 & 21.03 & 29 & .858 \\
\hline 30 & .128 & .087 & 23.19 & 30 & .807 \\
\hline 31 & -.083 & .085 & 24.14 & 31 & .805 \\
\hline 32 & -.169 & .082 & 28.34 & 32 & .652 \\
\hline 33 & .050 & .080 & 28.73 & 33 & .679 \\
\hline 34 & .044 & .077 & 29.06 & 34 & .708 \\
\hline 35 & .118 & .075 & 31.54 & 35 & .635 \\
\hline
\end{tabular}

a. The underlying process assumed is independence (white noise).

b. Based on the asymptotic chi-square approximation.

The soil temperature data was measured and obtained from the designed temperature data monitoring system at $5 \mathrm{~cm}$, $10 \mathrm{~cm}$ and $20 \mathrm{~cm}$ depths continuously from 12th April to 22nd April, 2013. Fig. 3 shows the graphic user interface of microcontroller temperature monitoring system. A paired t-test was used to compare the means of the reading from the temperature data monitoring system with a standard thermometer. Tables 1 show average reading taken on April 14, 2013 for twenty four readings each from the designed and the standard thermometer at NIMEX station spread over twelve hours in the morning, after moon, and evening. The results show that all the $\mathrm{p}$-values of the model terms were significant i.e $\mathrm{p}<0.05$. The pair samples correlation between the designed system and standard thermometer at $5 \mathrm{~cm}$ and $10 \mathrm{~cm}$ soil depths were all remarkably significant model terms at $97 \%$ and $98 \%$ confidence level. This shows that there is a significant correlation between the designed system and standard thermometer. A time series graph of Soil temperature in Fig. 4 compares the readings from the designed soil temperature system with an existing one (NIMEX weather station on O.A.U site) at $5 \mathrm{~cm}$ soil depth. It was observed that these time series graph generated followed a similar wave amplitude pattern. However, there exist slight variations probably because they were not exactly at the same point and some soil properties could have also caused the slight variation, which can be attributed to air pockets in the soil or moisture content variations across the distance.

Table 3. Checking for Autocorrelations in Series T2_10

\begin{tabular}{|c|c|c|c|c|c|}
\hline \multirow{2}{*}{ Lag } & \multirow{2}{*}{ Autocorrelation } & \multirow{2}{*}{ Std. Errora } & \multicolumn{3}{|c|}{ Box-Ljung Statistic } \\
\hline & & & Value & df & Sig.b \\
\hline 1 & -.097 & .139 & .489 & 1 & .484 \\
\hline 2 & -.123 & .137 & 1.298 & 2 & .522 \\
\hline 3 & -.061 & .136 & 1.503 & 3 & .682 \\
\hline 4 & .210 & .134 & 3.955 & 4 & .412 \\
\hline 5 & .226 & .133 & 6.843 & 5 & .233 \\
\hline 6 & .095 & .131 & 7.370 & 6 & .288 \\
\hline 7 & -.171 & .130 & 9.113 & 7 & .245 \\
\hline 8 & .064 & .128 & 9.366 & 8 & .312 \\
\hline 9 & .067 & .127 & 9.644 & 9 & .380 \\
\hline 10 & .200 & .125 & 12.19 & 10 & .272 \\
\hline 11 & -.150 & .123 & 13.67 & 11 & .252 \\
\hline 12 & .016 & .122 & 13.68 & 12 & .321 \\
\hline 13 & -.075 & .120 & 14.08 & 13 & .368 \\
\hline 14 & .079 & .118 & 14.52 & 14 & .411 \\
\hline 15 & -.092 & .117 & 15.14 & 15 & .441 \\
\hline 16 & -.046 & .115 & 15.30 & 16 & .502 \\
\hline 17 & .010 & .113 & 15.31 & 17 & .573 \\
\hline 18 & -.156 & .111 & 17.27 & 18 & .505 \\
\hline 19 & .024 & .110 & 17.31 & 19 & .568 \\
\hline 20 & -.029 & .108 & 17.39 & 20 & .627 \\
\hline 21 & -.162 & .106 & 19.74 & 21 & .537 \\
\hline 22 & -.069 & .104 & 20.18 & 22 & .571 \\
\hline 23 & -.048 & .102 & 20.40 & 23 & .617 \\
\hline 24 & .010 & .100 & 20.41 & 24 & .673 \\
\hline 25 & -.067 & .098 & 20.88 & 25 & 699 \\
\hline 26 & -.072 & .096 & 21.44 & 26 & .719 \\
\hline 27 & -.059 & .094 & 21.83 & 27 & .746 \\
\hline 28 & -.106 & .092 & 23.18 & 28 & .724 \\
\hline 29 & .016 & .089 & 23.21 & 29 & .767 \\
\hline 30 & .085 & .087 & 24.15 & 30 & .765 \\
\hline 31 & -.092 & .085 & 25.32 & 31 & .753 \\
\hline 32 & -.144 & .082 & 28.39 & 32 & .650 \\
\hline 33 & .026 & .080 & 28.50 & 33 & .691 \\
\hline 34 & .080 & .077 & 29.57 & 34 & .685 \\
\hline 35 & .113 & .075 & 31.86 & 35 & .620 \\
\hline
\end{tabular}

a. The underlying process assumed is independence (white noise).

b. Based on the asymptotic chi-square approximation.

\subsection{Spatial and Temporal Variations in Measured Soil Temperature}

The measured soil temperature at 5,10 , and $20 \mathrm{~cm}$ depth for the period study are presented in Fig. 5. It shows the diurnal 
cycle of the soil temperature, read from the designed temperature system. A sinusoidal pattern was observed for the soil temperature variation as observed by Fourier series of 1822. This characteristic is inline with a typical soil temperature behavior. A wide variation was observed for top soil while the wave amplitude decreased down the profile of the soil. Soil temperature varies as the result of radiant, thermal and latent energy exchange processes which take place primarily through the soil surface, as heat propagates into the underground it diffuses (Beltrami et al., 2003). In the morning before sunrise, the minimum temperature of the soil was lowest at the surface and increases with depth. As the sun begins around 9.30 the surface temperature (temp_5cm) was about $30^{\circ} \mathrm{C}$ while the temperature at $10 \mathrm{~cm}$ depth (temp_10 $\mathrm{cm}$ ) was $34^{\circ} \mathrm{C}$. This shows that heat is leaving the soil at this time. Because of the time lag associated with heat flow when surface temperature is changing, the lower depth continues to cool for a period of time. Since the source of heat at the surface is periodic, it is reasonable to assume that far below the surface; the soil will stay at average temperature (Jury and Robert, 2004).

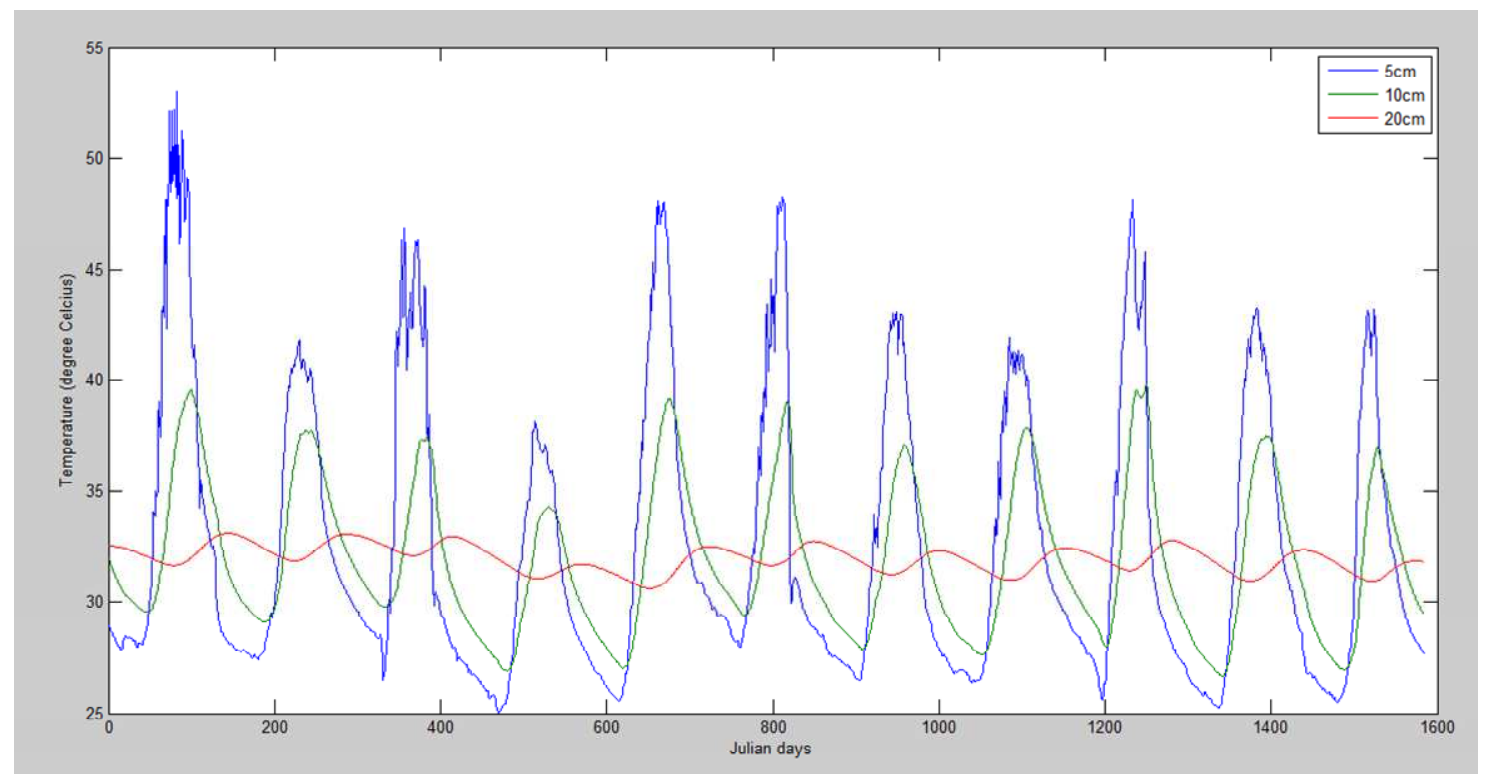

Fig 5. Time Series of Soil Temperature at Different Depth from $12^{\text {th }}$ April to $22^{\text {nd }}$ April, 2013 at NIMEX Metrological Station, Department of Physics, O.A.U, Ile-Ife.

\subsection{Prediction Analysis and the Results}

The soil temperature at 5 and $10 \mathrm{~cm}$ depths was modeled for forecasting. The original readings were 144 observations of 10 minutes interval taken throughout the day (i.e. 24 hours or 1440 minutes). The weekly average was computed and used for this analysis. The estimated period was from week 14, 2012 starting from April 1, 2012 to Week 10, 2013 starting from March10, 2013. while the forecasted period was from week 11, 2013 starting from March 10, 2013 to Week 35, 2013 starting from August 26, 2013. It was observed that the pattern of the graphs of the original series autocorrelation function (ACF) for T1_5 Series and T2_10 series shown in Figs.6 and 7 as sample $\overline{\mathrm{ACF}}$ of $\mathrm{T} 15^{-}$and $\mathrm{T} 2 \_10$ series indicates non-stationarity, because the graph cuts the confidence limits at several points. This series exhibited some elements of seasonality, which necessitated the series to be differenced to attain stationarity as well as removing the seasonal effect. It was also observed that there no significant autocorrelation in the T1 5 and T2 10 series in Tables 2 and 3 achieved after first differences were taken, since the $\mathrm{p}$-values of the model terms were significant. Stationarity was therefore achieved by applying the method of differencing shown in Figs. 8 and 9, indicated that both the upper and lower confidence intervals dies down. The Figs. 10 and 11 show the time series plot of
T1 5 and T2 10 series before and after taking the first-order differencing. It was observed that general downward trend at week 31 in Fig. 10 has now disappeared and replace by peaks and troughs in Fig. 11 of various week, but of non-periodic interval. The spikeless graph produced at first differencing at various lags suggests fitting a non-seasonal $\operatorname{ARIMA}(0,1,0)$ into the series. This series with different characteristics was modeled in order to determine the stability of the parameter estimation. The method of maximum likelihood was used to determine the estimates of the parameters of the identified models and each parameter was statistically tested for significance. The plots of the ordinary differenced series autocorrelation function suggested some models for selection, but the Normalized Bayesian Information Criterion (Normalized BIC) was used to select the model that really provided the best fit for the series. From the family of the identified models, ARIMA $(0,1,0)$ model was found to be the most adequate model that really captured the dependence in the series. The performance evaluations of the adopted model, carried out on the basis of correlation coefficient (R2), Root Mean Square Error (RMSE), Mean Percentage Error (MAPE), Maximum Absolute Percentage Error (MaxAPE) and Ljung-Box statistics with values of $0.95,0.57,1.39,3.94$, 13.58 and $0.96,0.46,1.11,4.11,19.75$ respectively for soil 
temperature at $5 \mathrm{~cm}$ and $10 \mathrm{~cm}$ soil depths.

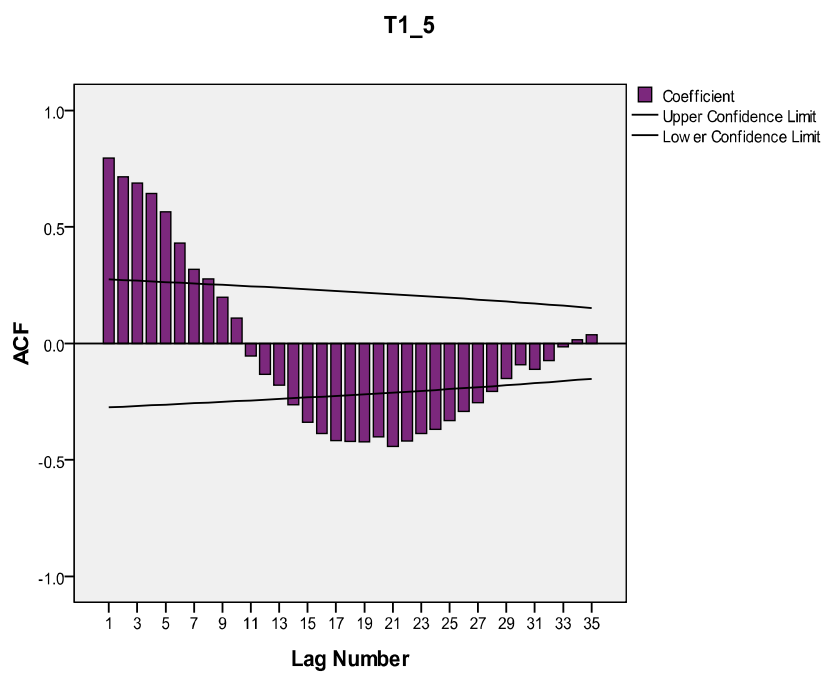

Fig 6. Sample ACF of $T 1 \_5$ Series

\section{T2_10}

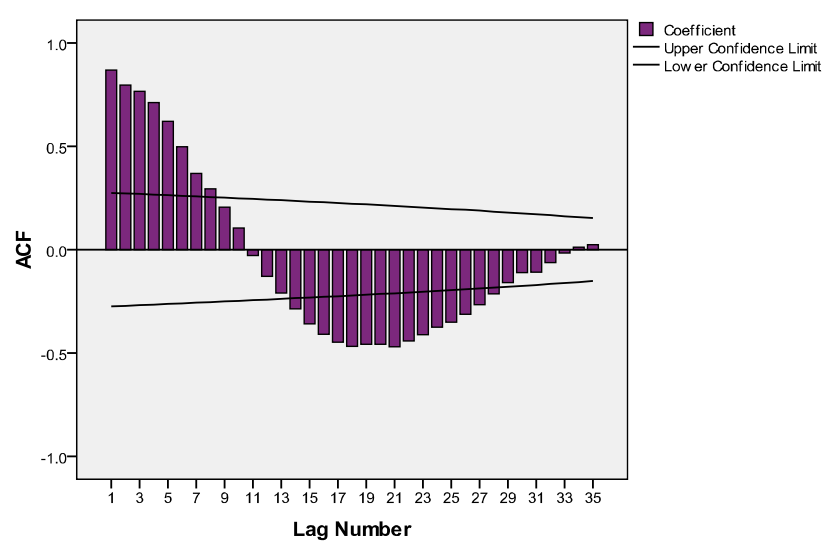

Fig 7. Sample ACF of T2_10 Series

T1_5

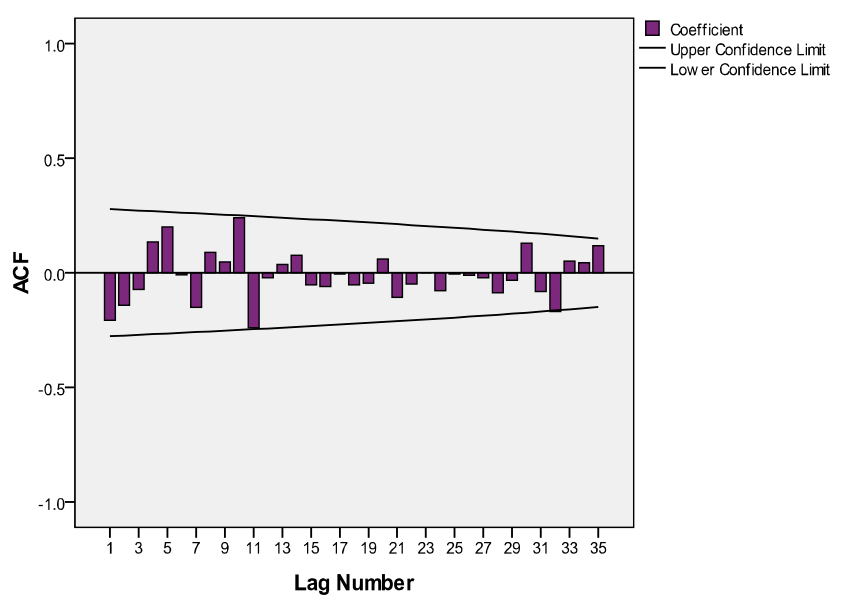

Fig 8. Sample ACF of T1_5 Series (After First Differencing)
T2_10

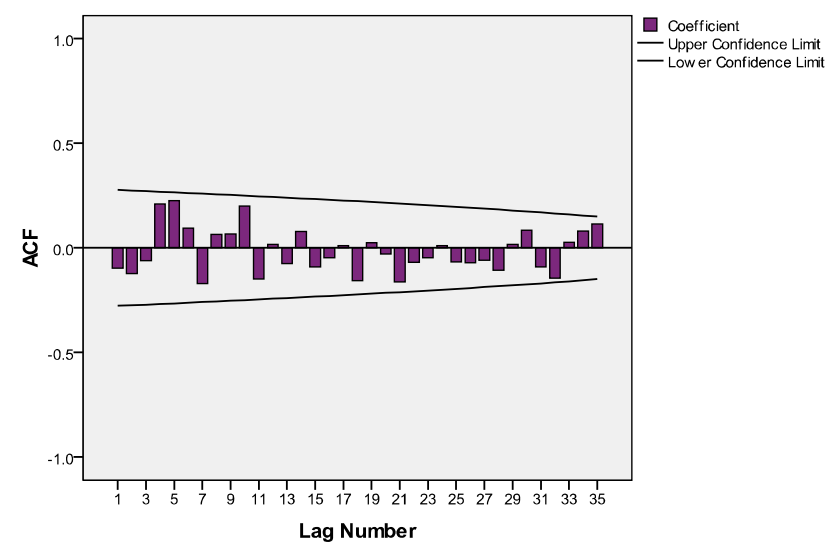

Fig 9. Sample ACF of T2_10 Series (After First Differencing)

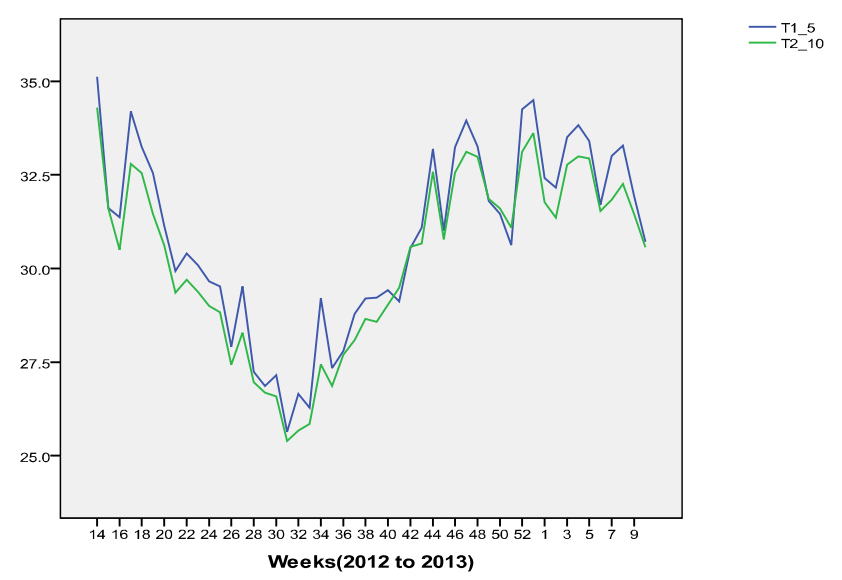

Fig 10. Observed Values before First Differencing of Soil Temperature at 5 and $10 \mathrm{~cm}$ Soil Depths (Note: weeks are represented as observations from 14 to 9)

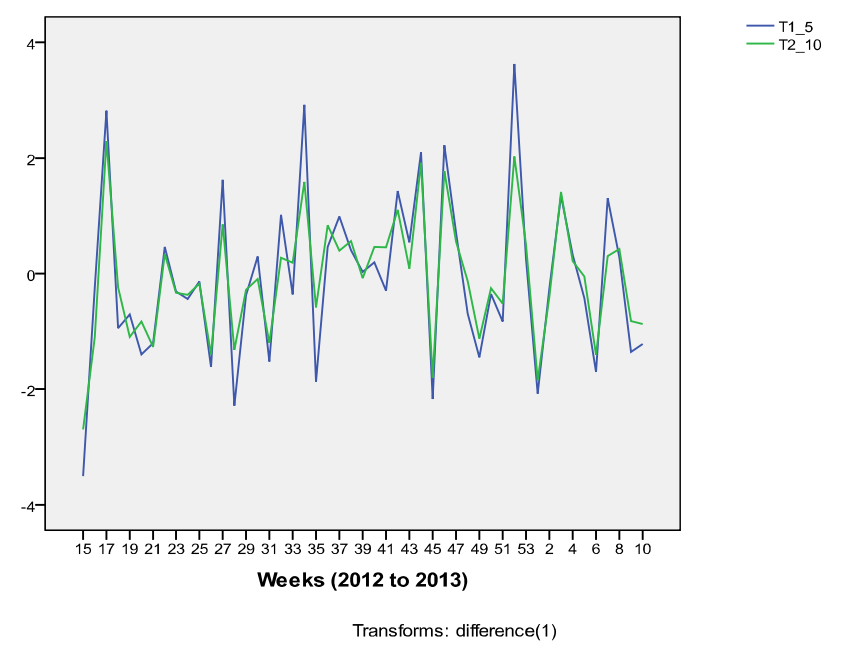

Fig 11. Graph of Observed Values after First Differencing of Soil Temperature at 5 and $10 \mathrm{~cm}$ Soil Depths (Note: weeks are represented as observations from 14 to 9)

The model was used for a short term forecast (week 11week 35, 2013), shown in Figs. 12 and 13 respectively for soil temperature at $5 \mathrm{~cm}$ and $10 \mathrm{~cm}$ soil depths. The result of the analysis from the soil temperature predicted graph at $5 \mathrm{~cm}$ soil 
depth shown in Fig. 12 that between weeks 21- 43 and weeks 18 - 35 fell between $10^{\circ} \mathrm{C}$ and $30^{\circ} \mathrm{C}$. Within these periods, maize seeds could be planted. This farm practice information, which gives the appropriate sowing date, was successfully sent to remote phone as advice, using GSM/GPRS system via this application in the computer. Figs. 14, 15 and 16 show this SMS platform application.

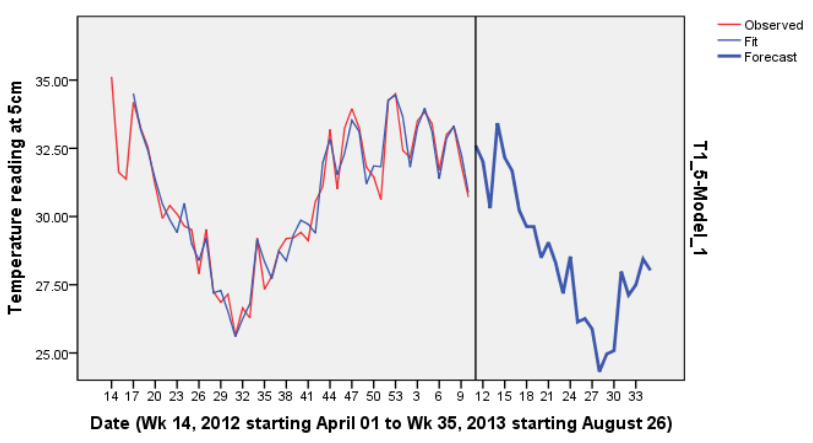

Fig 12. Graph of Observed and Predicted Values Soil Temperature at $5 \mathrm{~cm}$ Soil Depth

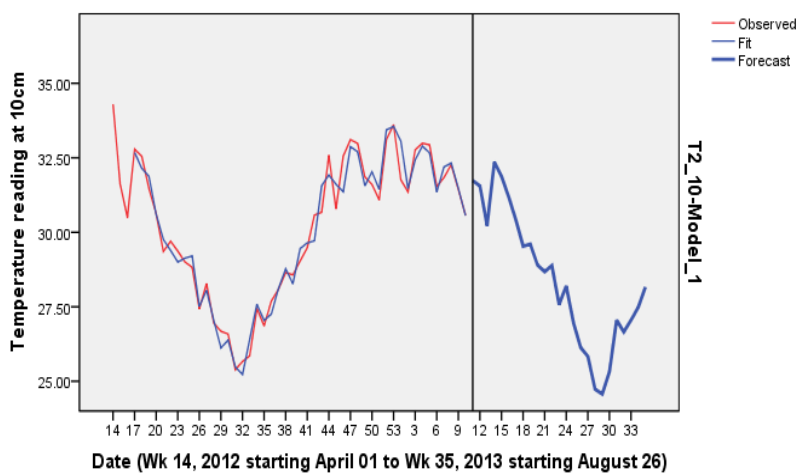

Fig 13. Graph of Observed and Predicted Values for Soil Temperature at $10 \mathrm{~cm}$ soil Depth

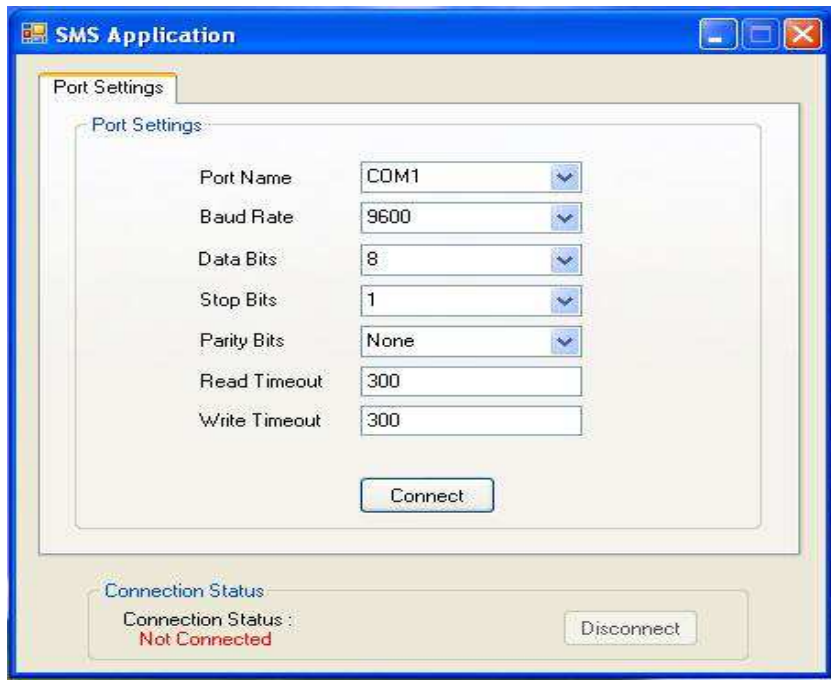

Fig 14. Port settings for SMS Application

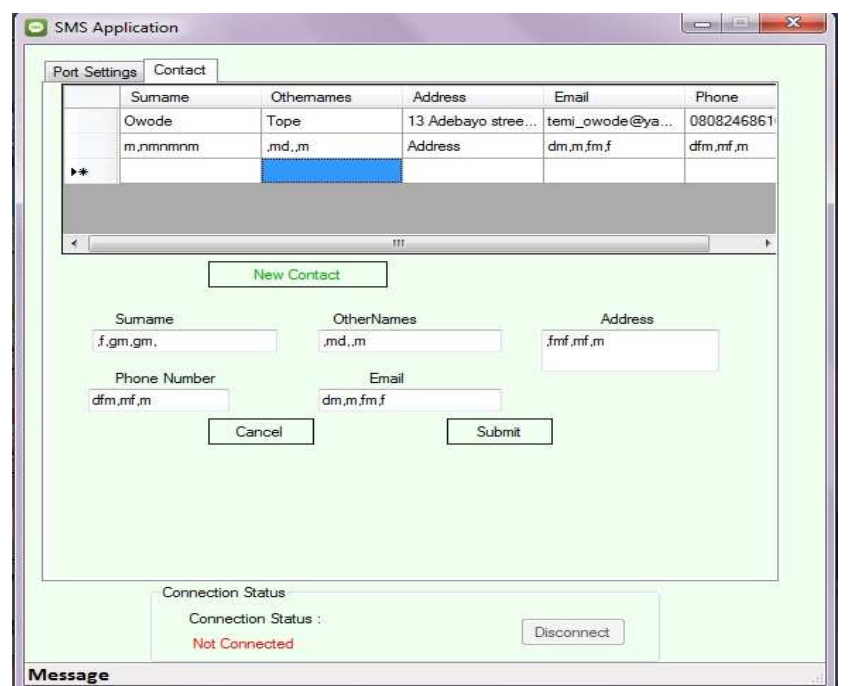

Fig 15. Contact for SMS Application

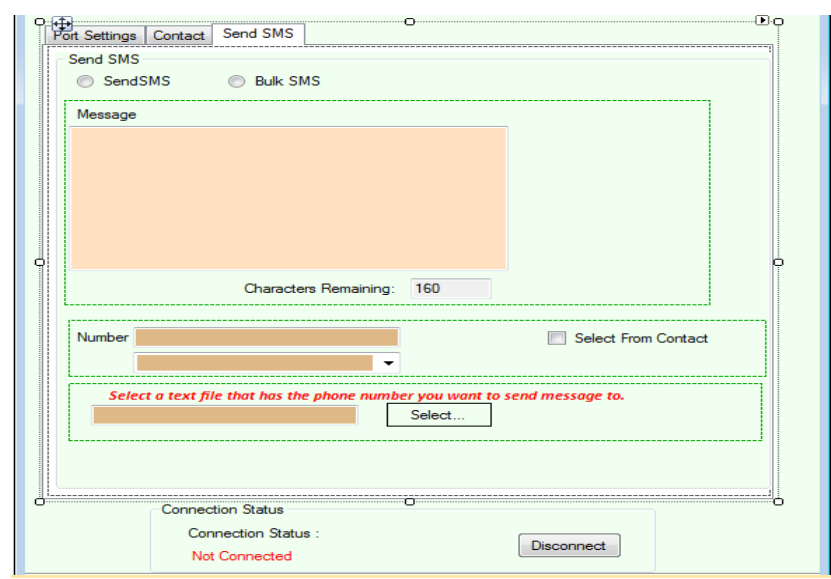

Fig 16. Application Platform for Sending SMS Message

\section{Conclusion}

The production of inexpensive tool for monitoring soil temperature was designed and tested successfully. It provided a low cost alternative to the current commercial systems in monitoring soil temperature. This device was able to monitor soil temperature at varying depths over a period of time on clay loam soil at NIMEX station. The data obtained was not statistically different from the one obtained from analogue thermometer and time-tested thermometer. The task of fitting a parsimonious time series model as the case of this study using the time-tested thermometer series as inputs was achieved, using the established principles and guidelines of model-building in series modeling approach. The series was seemed to be non-stationary and there were elements of seasonality as evidenced the series ACF. The series was subsequently differenced to ensure stationarity and also to ensure that seasonal effect was reduced in order for the series to be parsimoniously modeled. Parameter estimation of all identified models was done using the maximum likelihood approach. The identified model was tested for adequacy using the ARIMA model parameters, statistics model and model fit of the model. All confirmed the adequacy of the chosen model 
from the family of all identified models. A consideration was given to a model with a minimum Normalized BIC with fewer parameters which also displayed a valid signature in the autocorrelation function. The output of this analysis that serves as farm practice information which determined the planting period for maize was sent to the phones of registered farmers, through the developed SMS application. This information which is in form of advice helps them to determine when to plant their crops. This method serves as an improve access to information based on the monitored soil temperature. It is believed that the methods described in this report, concerned with the relationship of soil temperature to maize planting period, could be adapted to the study of any type of plant growth.

\section{References}

[1] Adelekun, M. (2012) Design and construction of a Temperature Data Logger System for Soil Temperature Measurement, Unpublished M.Sc Thesis, Obafemi Awolowo University 134p

[2] Al-Ali, A.R.; Al-Rousan, M., (2004); "Java-based home automation system", IEEE Transactions. on Consumer Electronics, vol. 50, Issue 2, pp. 498 - 504, 2004

[3] Aina, L.O. (2007). Globalisation and Small- Scale Farming in Africa: What role for Information Centres? World libraries and information congress 73rd IFLA General Conference and Council. Durban, South Africa.

[4] Beltrami, H. and Kellman, L.(2003) An Examination of shortand Long-term air- ground Temperature Coupling, Global and Planetary Change 38: 291- 303.

[5] Gavito, M.E., Curtis, P.S., Mikkelsen, and T.N., Jakobsen, I.,(2001) Interactive effects of soil uptake temperature, atmospheric carbon dioxide and soil $\mathrm{N}$ on root developm biomass and nutrient of winter wheat during vegetative growth. Journal of Experimental Botany 52, 1913-1923.
[6] Jury, w. A. and Robert, H. (2004) Soil Thermal Regime. Soil Physics 6th ed.. John Wiley and Sons Inc. Hoboken, New jersey. Pg 176-186.

[7] Munyua, H. (2000) Application of information communication technologies in the agricultural sector in Africa: a gender perspective. In: Rathgeber, E, and Adera, E.O. (Eds.) Gender and information Revolution in Africa IDRC/ECA. Pp. 85-123

[8] Ogallo, L. (2010) the Mainstreaming of Climate Change and Variability Information into Planning and Policy Development. Procedia Environmental Sciences 1: 405-410.

[9] Pulwarty, R., S., Olanrewaju, S., and P. Zorba (2009) Communicating Agro climatological information, including forecasts, for agricultural decisions. Guide to Agro-Meteorological Practices WMO Commission for Agricultural and Meteorological Practices Available from http://www.wmo.ch/web/wcp/agm/RevGAMP/

[10] Raleigh, C. and Urdal, H. (2007) Climate Change, Environmental Degradation and Armed Conflict Political Geography 26 674-694

[11] Ramamurthy, .B., Bhargavi, S. and ShashiKumar, R.(2010) Development of a Low-Cost GSM SMS-Based Humidity Remote Monitoring and Control system for Industrial Applications,International Journal of Advanced Computer Science and Applications, Vol. 1, No. 4.

[12] Romilly, P.( 2005) Time series modeling of global mean temperature for managerial decision making. Journal of Environmental Management, 76, 61-70.

[13] UNFCC. (2007) Climate Change: Impacts, Vulnerabilities and Adaptation in Developing Countries. Available at unfccc. int/resource/docs/publications/impacts.pdf. 